\title{
Solubility of Two Resin Composites in Different Mouthrinses
}

\author{
Sezin Ozer, ${ }^{1}$ Emine Sen Tunc, ${ }^{1}$ Nuray Tuloglu, ${ }^{2}$ and Sule Bayrak ${ }^{2}$ \\ ${ }^{1}$ Faculty of Dentistry, Department of Pediatric Dentistry, Ondokuz Mayts University, Kurupelit, 55139 Samsun, Turkey \\ ${ }^{2}$ Department of Pediatric Dentistry, Faculty of Dentistry, Eskisehir Osmangazi University, Eskisehir, Turkey
}

Correspondence should be addressed to Sezin Ozer; sezinsezgin78@yahoo.com

Received 19 February 2014; Accepted 20 March 2014; Published 7 April 2014

Academic Editor: David M. Dohan Ehrenfest

Copyright (C) 2014 Sezin Ozer et al. This is an open access article distributed under the Creative Commons Attribution License, which permits unrestricted use, distribution, and reproduction in any medium, provided the original work is properly cited.

\begin{abstract}
Aim. This study aimed to compare the solubility of a universal restorative resin composite (Filtek Z250; FZ250) and a silorane-based resin composite (Filtek Silorane; FS) after immersion in alcohol-containing mouthrinse, alcohol-free mouthrinse, and artificial saliva. Methods. 30 discs $(10 \mathrm{~mm} \times 1 \mathrm{~mm})$ were prepared from each material and desiccated until a constant mass was obtained. Specimens were immersed in the test solutions for two days and desiccated again. Solubility was calculated based on the change in weight of each specimen before and after immersion. Data was analyzed using two-way ANOVA and Tukey's Post Hoc test $(P<0.05)$. Results. Solubility values for both resin composites were the highest in the alcohol-containing mouthrinse. FZ250 showed greater solubility than FS; the difference was only significant in artificial saliva. Conclusion. Both resin-composite materials tested exhibited some degree of solubility in each of the test solutions. The use of an alcohol-free mouthrinse may be preferable for patients with extensive composite restorations.
\end{abstract}

\section{Introduction}

Dental composites constitute an important group of materials in modern restorative dentistry [1]. Composites-which generally consist of a resin matrix, inorganic filler, and coupling agent-are becoming more and more popular as dental restorative materials because of their strength, rapid polymerization, and esthetic appearance [2]. However, polymerization shrinkage and shrinkage-related stress are two major drawbacks of resin composites that still need to be addressed. In order to overcome these shortcomings, dental siloranes consisting of a new type of organic matrix (i.e., monomers with a ring-opening oxirane) were introduced in 2007 [3].

Upon intraoral application, resin composites face constant exposure to an aqueous environment. Water diffused into the resin matrix may contribute to the relaxation of polymerization shrinkage stress to some extent [4], and, by expanding the polymer matrix and increasing the bulk volume of the resin composite, water sorption may reduce the size of marginal gaps generated by polymerization shrinkage [5]. On the other hand, water sorption may lead to degradation of the resin matrix and debonding of the matrixfiller interface, resulting in a deterioration of mechanical properties. In addition, leakage of fillers, ions, and organic substances such as residual monomers, methacrylic acid, and formaldehyde from resin composite material can occur as a result of exposure to an aqueous environment. Some of these organic substances are potent irritants and may induce delayed allergic reactions. Both material degradation and leakage have been shown to be dependent upon time and material composition [6].

Effective plaque control is crucial for the maintenance of periodontal health and control of cariogenic activity. For most individuals, toothbrushing with a dentifrice is the most efficient, safe and economical method of removing plaque; however, many individuals find it difficult to achieve a plaque-free dentition with this method alone. While the use of an antiseptic agent such as a mouthrinse as an adjunct to toothbrushing with a dentifrice may be justified, especially in caries-active patients $[7,8]$, the detrimental effects of mouthrinses on resin composite restorations must be taken into account [9].

The organic matrix of conventional resin composites is generally based on methacrylate chemistry, especially crosslinking dimethacrylates. The solubility of dimethacrylatebased resin composites in various solutions including water 
and mouthrinses has been widely studied [2, 10-12]; however, few studies have been carried out on silorane-based resin composites [13-15]. Therefore, this study aimed to measure the solubility of two different resin composites in three different solutions: an alcohol-free mouthrinse, an alcoholcontaining mouthrinse, and artificial saliva [16]. The null hypothesis was that solubility values would not differ, regardless of the restorative material or solution tested.

\section{Materials and Methods}

2.1. Restorative Materials and Solutions. This study employed a randomized factorial design conducted with 10 replications of 2 different restorative materials (FZ250 and FS) and 3 different solutions (artificial saliva, an alcohol-free mouthrinse (Oral-B, Pro-Expert), and an alcohol-containing mouthrinse (Oral-B, Advantage)) (Table 1).

2.2. Preparation of Specimens. For each material, a total of 30 disc-shaped specimens were prepared using a plastic mold $(1 \pm 0.1 \mathrm{~mm} \times 10 \pm 0.1 \mathrm{~mm})$. The mold was filled and pressed by hand between two glass microscope slides to extrude any excess material. Specimens were light-cured on both sides and in different positions for a total of 60 seconds using an LED curing unit (Elipar Free Light II, $3 \mathrm{M} / \mathrm{ESPE}$, St. Paul, MN, USA; light intensity: $1000 \mathrm{mV} / \mathrm{cm}^{2}$ ). Specimens were removed from the molds, and any excess material was removed by gently grinding on both sides with 600grit silicon carbide paper (Phoenix Beta, Buehler, Germany). Debris was removed with a dust blower.

2.3. Solubility Measurements. Solubility measurements were conducted in line with ISO 4049 standards [17]. A digital caliper (Digimatic Caliper, Mitutoyo, Tokyo, Japan; accuracy $=0.002 \mathrm{~mm}$ ) was used to measure diameter and thickness. The diameter of each specimen was measured at two points at right angles to one another, and the mean diameter was calculated. The thickness of each specimen was measured at the center of the specimen and at four equally spaced points on the circumference, and the mean thickness was calculated. The volume $(V)$ of each specimen was calculated in $\mathrm{mm}^{3}$ using the formula $V=\pi \times r^{2} \times h$, where $r$ is the mean sample radius (diameter/2) and $h$ is the mean sample thickness.

For each material, 10 specimens were placed in a glass vial containing $10 \mathrm{~mL}$ of artificial saliva, 10 in a glass vial containing $10 \mathrm{~mL}$ of alcohol-free mouthrinse (Oral-B, Pro-Expert) and 10 in a glass vial containing $10 \mathrm{~mL}$ of alcohol-containing mouthrinse (Oral-B, Advantage). Vials were wrapped in aluminum foil to exclude light and placed in an incubator at $37^{\circ} \mathrm{C}$.

Specimens were weighed using an analytical scale accurate up to $0.0001 \mathrm{mg}$ (Precise XB 220A, Switzerland). All specimens were stored in a vacuum desiccator at $37^{\circ} \mathrm{C}$ until a constant weight $\left(m_{0}\right)$ was obtained. Specimens were then immersed in the solutions for 2 days, removed, and desiccated again until a constant mass was obtained, and the weights were recorded again $\left(m_{1}\right)$. Solubility $(\mathrm{SL})$ was recorded in $\mu \mathrm{g} / \mathrm{mm}^{3}$ as the change in weight before and after immersion using the formula SL $=m_{0}-m_{1} / V$, where $V$ is the volume of the sample in $\mathrm{mm}^{3}$.

2.4. Statistical Analysis. Statistical analysis was conducted using the software SPSS 12.0 (SPSS Software, Munich, Germany). Means and standard deviations were calculated, and multiple comparisons were performed using two-way ANOVA and Tukey's Post Hoc test, with a level of $P<0.05$ considered statistically significant.

\section{Results}

Means, standard deviations, and significant differences in solubility are presented in Table 2 . Solubility values of FS were lower than those of FZ250 in each of the solutions tested; however, these differences were only statistically significant in artificial saliva $(P<0.05)$. Although no statistically significant differences were observed between the solubility values of the same material in different mouthrinses $(P>$ $0.05)$, solubility values for both materials were higher in the alcohol-containing mouthrinse than in the alcohol-free mouthrinse.

\section{Discussion}

The current study found the solubility of the universal resin composite FZ250 to be higher than that of the silorane resin composite FS; however, the difference between the two was only statistically significant in artificial saliva $(P<0.05)$. Thus, the null hypothesis was accepted, with the exception of solubility performance in artificial saliva.

Excessive solubility of dental restorative materials can lead to surface deformation and marginal discrepancies. Resin composite materials come into extensive contact with oral fluids, food components, and drinks in the oral environment [18], and while the solubility of dimethacrylatebased resin composites in different solutions has been widely studied [2, 10-12], to our knowledge, there is very little information available regarding the solubility of siloranebased resin composites [13-15]. Therefore, the present study aimed to evaluate the solubility of FS and FZ250 in 3 different solutions.

Solubility mean values presented by the composite resins tested varied from 2.3 to $4.2 \mu \mathrm{g} / \mathrm{mm}^{3}$; these values were lower than the maximum value established by the ISO 4049 standard $\left(<7.5 \mu \mathrm{g} / \mathrm{mm}^{3}\right)$ [17]. Although the direct exploration is not possible, the results of the present study showed that the solubility of all materials in all solutions is acceptable for ISO 4049.

With the exception of artificial saliva, the solubility of FS and FZ250 did not differ significantly $(P>0.05)$; however, the solubility of FZ250 was greater than that of FS. It is likely that the low solubility of FS is related to the distinctive polymerization characteristics of the material. This finding is consistent with a previous study showing silorane-based resin composites to be more hydrophobic than methacrylate-based resin composites $[13,19]$. The solubility 
TABLE 1: Materials used in the study.

\begin{tabular}{|c|c|c|c|}
\hline Material & Contents & Lot no & Manufacturer \\
\hline Filtek Z250 universal restorative & $\begin{array}{l}\text { Bisphenol A polyethyleneglycol diether dimethacrylate } \\
\text { (bis-EMA) }(5-10 \% \text { by wt), silane treated ceramic }(75-85 \% \text { by } \\
\text { wt), urethane dimethacrylate (UDMA) }(5-10 \% \text { by wt), } \\
\text { bisphenol-A-glycidyl dimethacrylate (Bis-GMA) }(<5 \% \text { by } \\
\text { wt), triethyleneglycol dimethacrylate (TEGDMA) }(<5 \% \text { by } \\
\text { wt), and water } \\
\text { Filled to } 60 \% \text { by volume with zircon silica filler, average } \\
\text { particle size }=0.6 \mu \mathrm{m}\end{array}$ & $8 \mathrm{FA}$ & $\begin{array}{l}\text { 3M/ESPE, St. Paul, MN, } \\
\text { USA }\end{array}$ \\
\hline $\begin{array}{l}\text { Filtek Silorane (posterior } \\
\text { restorative) }\end{array}$ & $\begin{array}{l}\text { Silorane (3,4-epoxycyclohexylethylcyclo-polymethylsiloxane, } \\
\text { bis-3,4-epoxycyclohexylethyl-phenylmethylsilane) } \\
\text { Fillers: Quarz (silane layer) radiopaque yttrium fluoride } \\
\text { Filler loading 76\% (wt \%) }\end{array}$ & N236344 & $\begin{array}{l}\text { 3M/ESPE, St. Paul, MN, } \\
\text { USA }\end{array}$ \\
\hline $\begin{array}{l}\text { Oral-B, Pro-Expert mouthrinse } \\
\text { (alcohol-free mouthrinse) }\end{array}$ & $\begin{array}{l}\text { Aqua, Glycerin, polysorbate } 20 \text {, Aroma, methylparaben, } \\
\text { cetylpyridinium chloride, sodium fluoride, sodium saccharin, } \\
\text { sodium benzoate, propylparaben, } \mathrm{Cl} 42051 \text {, and } \mathrm{Cl} 47005\end{array}$ & 99602155 & $\begin{array}{c}\text { Procter \& Gamble MN } \\
\text { GmbH, Stra } \beta \text { e e 1, } 64521 \\
\text { Gross Gerau, Germany }\end{array}$ \\
\hline $\begin{array}{l}\text { Oral-B, Advantage mouthrinse } \\
\text { (alcohol-containing mouthrinse) }\end{array}$ & $\begin{array}{l}\text { Aqua, glycerin, alcohol, aroma, methylparaben, poloxamer } \\
\text { 407, cetylpyridinium chloride, sodium fluoride, sodium } \\
\text { saccharin, Propylparaben, } \mathrm{Cl} 42051 \text {, and } \mathrm{Cl} 47005\end{array}$ & 95587215 & $\begin{array}{l}\text { Procter \& Gamble UK, } \\
\text { Weybrige, KT13 0XP }\end{array}$ \\
\hline Artificial saliva & $\begin{array}{l}\mathrm{NaCl}(400 \mathrm{mg} / \mathrm{L}), \mathrm{KCL}(400 \mathrm{mg} / \mathrm{L}), \mathrm{CaCl}_{2} \cdot 2 \mathrm{H}_{2} \mathrm{O}(795 \mathrm{mg} / \mathrm{L}) \\
\mathrm{NaH}_{2} \mathrm{PO}_{4} \cdot \mathrm{H}_{2} \mathrm{O}(690 \mathrm{mg} / \mathrm{L}) \mathrm{KSCN}(300 \mathrm{mg} / \mathrm{L}), \mathrm{Na}_{2} \mathrm{~S} \cdot 9 \mathrm{H}_{2} \mathrm{O} \\
(5 \mathrm{mg} / \mathrm{L}) \text {, and urea }(1000 \mathrm{mg} / \mathrm{L})\end{array}$ & & \\
\hline
\end{tabular}

TABLE 2: Mean solubility values of materials tested $\left(\mu \mathrm{g} / \mathrm{mm}^{3}\right)$.

\begin{tabular}{lcc}
\hline \multirow{2}{*}{ Solutions } & \multicolumn{2}{c}{ Test materials } \\
& FZ250 (sd) & FS (sd) \\
\hline $\begin{array}{l}\text { Alcohol-containing mouth rinse } \\
\text { (advantage) }\end{array}$ & $4.2(1,4)^{(\mathrm{A}, 1)}$ & $3.1(1,7)^{(\mathrm{B}, 1)}$ \\
$\begin{array}{l}\text { Alcohol-free mouth rinse } \\
\text { (Pro-Expert) }\end{array}$ & $3.5(0,9)^{(\mathrm{A}, 1)}$ & $3.0(1,1)^{(\mathrm{B}, 1)}$ \\
Artificial saliva & $3.4(1,3)^{(\mathrm{A}, 1)}$ & $2.3(0,6)^{(\mathrm{B}, 2)}$ \\
\hline
\end{tabular}

Differences in superscript letters indicate statistically significant differences within columns and differences in superscript numbers indicate significant differences within rows.

of resin composites is related to the dissolution and leaching of various components, particularly unreacted monomers [20]. The organic matrix of conventional resin composites is generally based on methacrylate chemistry, especially cross-linking methacrylates, as in FZ250. The density of the links in methacrylate-based resin composites may vary as a result of the polymerization of free radicals, causing spatial heterogeneity that may facilitate the entrapment of residual monomers in microgels, from where they may be easily leached [21]. When compared to methacrylate-based resin polymerization, the photoactivated cationic polymerization process of silorane resins is relatively insensitive to oxygen. Not only does this reduce polymerization shrinkage, it also increases the degree of conversion [15, 22, 23].

Ethanol, which is found in many mouthrinses, may accelerate the hydrolytic degradation of resin-based materials [24]. In vitro studies have reproduced the subsurface and surface degradation of resin composites by storing them in ethanol [6], and the mechanical properties of composite resins have been compromised by aging them in alcoholcontaining solutions [9]. In the present study, both materials tested exhibited greater solubility in the mouthrinse containing alcohol when compared to the alcohol-free mouthrinse $(P>0.05)$. These findings suggest that it may be preferable for patients with extensive restorations to avoid the use of mouthrinse containing alcohol as part of their daily oral hygiene routine so as to prevent the need for recurrent restorative treatment.

As with all in vitro studies, caution must be used when extrapolating the results of the present study to the oral environment. Clinical studies are needed to examine the in vivo solubility behavior of different resin composites.

\section{Conclusion}

Within the limitations of this in vitro study, the following conclusions can be drawn:

(1) the solubility of FS was lower than that of FZ250 in all the solutions tested;

(2) solubility of both of the restorative materials tested was lower in alcohol-free mouthrinse than in alcohol mouthrinse containing;

(3) alcohol-free mouthrinse may prefer to alcohol containing mouthrinse in patients with extensive restorations.

\section{Conflict of Interests}

The authors declare that there is no conflict of interests. 


\section{References}

[1] W. Geurtsen and U. Schoeler, "A 4-year retrospective clinical study of class I and class II composite restorations," Journal of Dentistry, vol. 25, no. 3-4, pp. 229-232, 1997.

[2] Y. Zhang and J. Xu, "Effect of immersion in various media on the sorption, solubility, elution of unreacted monomers, and flexural properties of two model dental composite compositions," Journal of Materials Science: Materials in Medicine, vol. 19, no. 6, pp. 2477-2483, 2008.

[3] W. Weinmann, C. Thalacker, and R. Guggenberger, "Siloranes in dental composites," Dental Materials, vol. 21, no. 1, pp. 68-74, 2005.

[4] A. J. Feilzer, A. J. de Gee, and C. L. Davidson, "Relaxation of polymerization contraction shear stress by hygroscopic expansion," Journal of Dental Research, vol. 69, no. 1, pp. 36-39, 1990.

[5] T. Hirasawa, S. Hirano, S. Hirabayashi, I. Harashima, and M. Aizawa, "Initial dimensional change of composites in dry and wet conditions," Journal of Dental Research, vol. 62, no. 1, pp. 28-31, 1983.

[6] J. L. Ferracane, "Hygroscopic and hydrolytic effects in dental polymer networks," Dental Materials, vol. 22, no. 3, pp. 211-222, 2006.

[7] M. Addy, "Chlorhexidine compared with other locally delivered antimicrobials. A short review," Journal of Clinical Periodontology, vol. 13, no. 10, pp. 957-964, 1986.

[8] M. Addy and J. M. Moran, "Clinical indications for the use of chemical adjuncts to plaque control: chlorhexidine formulations," Periodontology 2000, vol. 15, no. 1, pp. 52-54, 1997.

[9] J. E. McKinney and W. Wu, "Chemical softening and wear of dental composites," Journal of Dental Research, vol. 64, no. 11, pp. 1326-1331, 1985.

[10] K. Asaoka and S. Hirano, "Diffusion coefficient of water through dental composite resin," Biomaterials, vol. 24, no. 6, pp. 975-979, 2003.

[11] L. Musanje and B. W. Darvell, "Aspects of water sorption from the air, water and artificial saliva in resin composite restorative materials," Dental Materials, vol. 19, no. 5, pp. 414-422, 2003.

[12] H. Koizumi, H. Satsukawa, N. Tanoue, T. Ogino, M. Nishiyama, and H. Matsumura, "Effect of metal halide light source on hardness, water sorption and solubility of indirect composite material," Journal of Oral Science, vol. 47, no. 4, pp. 165-169, 2005.

[13] W. M. Palin, G. J. P. Fleming, F. J. T. Burke, P. M. Marquis, and R. C. Randall, "The influence of short and medium-term water immersion on the hydrolytic stability of novel low-shrink dental composites," Dental Materials, vol. 21, no. 9, pp. 852-863, 2005.

[14] J. D. Eick, R. E. Smith, C. S. Pinzino, and E. L. Kostoryz, "Stability of silorane dental monomers in aqueous systems," Journal of Dentistry, vol. 34, no. 6, pp. 405-410, 2006.

[15] N. Ilie and R. Hickel, "Macro-, micro- and nano-mechanical investigations on silorane and methacrylate-based composites," Dental Materials, vol. 25, no. 6, pp. 810-819, 2009.

[16] H. H. Huang, Y. H. Chiu, T. H. Lee et al., "Ion release from NiTi orthodontic wires in artificial saliva with various acidities," Biomaterials, vol. 24, no. 20, pp. 3585-3592, 2003.

[17] EN ISO, 4049, Dentistry-Polymer-Based Filling, Restorative and Luting Materials, International Organization for Standardization, Geneva, Switzerland, 1988.
[18] R. Bagheri, M. F. Burrow, and M. Tyas, "Influence of foodsimulating solutions and surface finish on susceptibility to staining of aesthetic restorative materials," Journal of Dentistry, vol. 33, no. 5, pp. 389-398, 2005.

[19] Y. J. Wei, N. Silikas, Z. T. Zhang, and D. C. Watts, "Diffusion and concurrent solubility of self-adhering and new resin-matrix composites during water sorption/desorption cycles," Dental Materials, vol. 27, no. 2, pp. 197-205, 2011.

[20] P. L. Fan, A. Edahl, R. L. Leung, and J. W. Stanford, "Alternative interpretations of water sorption values of composite resins," Journal of Dental Research, vol. 64, no. 1, pp. 78-80, 1985.

[21] J. Malacarne, R. M. Carvalho, M. F. de Goes et al., "Water sorption/solubility of dental adhesive resins," Dental Materials, vol. 22, no. 10, pp. 973-980, 2006.

[22] N. Ilie and R. Hickel, "Silorane-based dental composite: behavior and abilities," Dental Materials Journal, vol. 25, no. 3, pp. 445-454, 2006.

[23] W. Lien and K. S. Vandewalle, "Physical properties of a new silorane-based restorative system," Dental Materials, vol. 26, no. 4, pp. 337-344, 2010.

[24] S. Y. Lee, H. M. Huang, C. Y. Lin, and Y. H. Shih, "Leached components from dental composites in oral simulating fluids and the resultant composite strengths," Journal of Oral Rehabilitation, vol. 25, no. 8, pp. 575-588, 1998. 

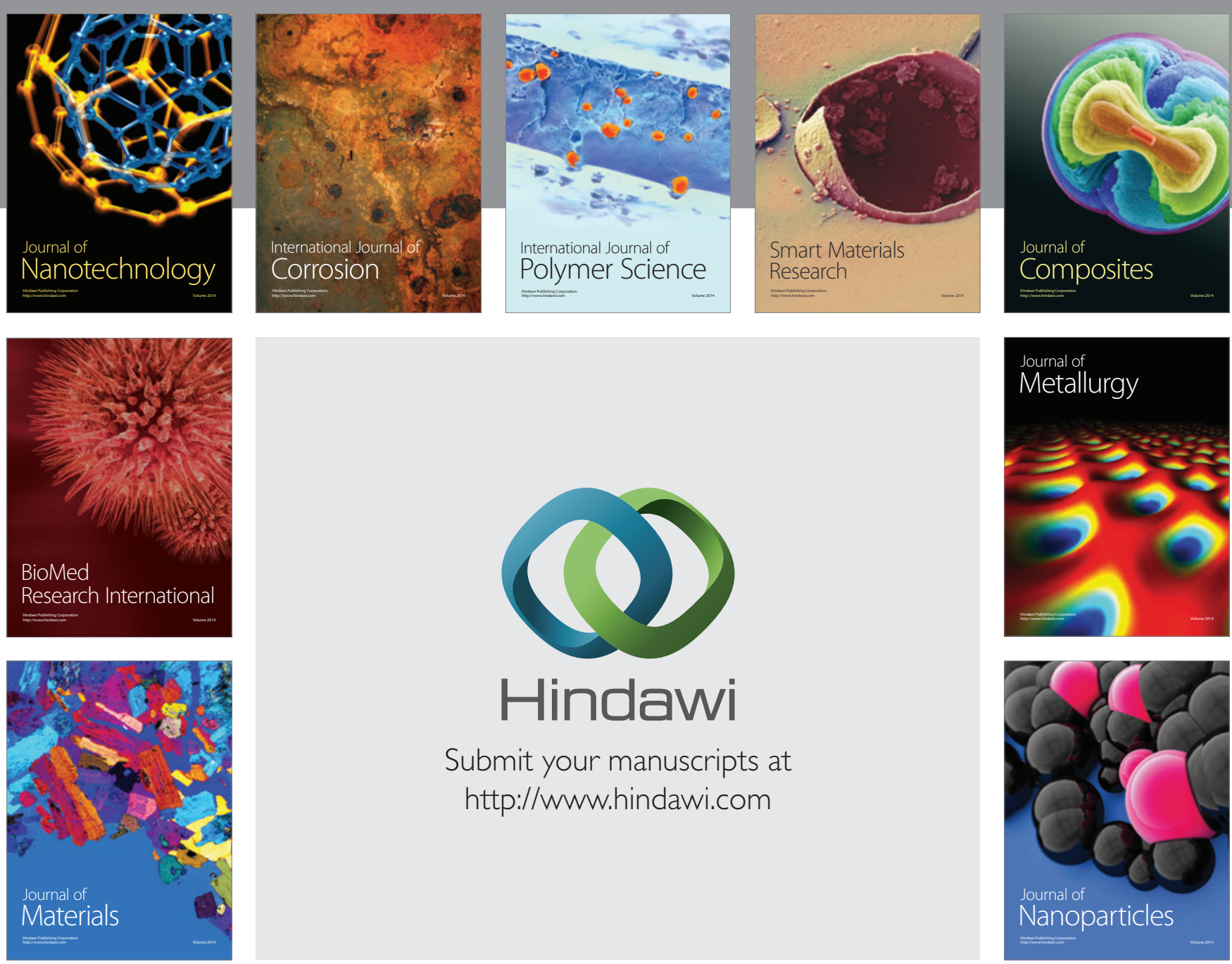

Submit your manuscripts at http://www.hindawi.com
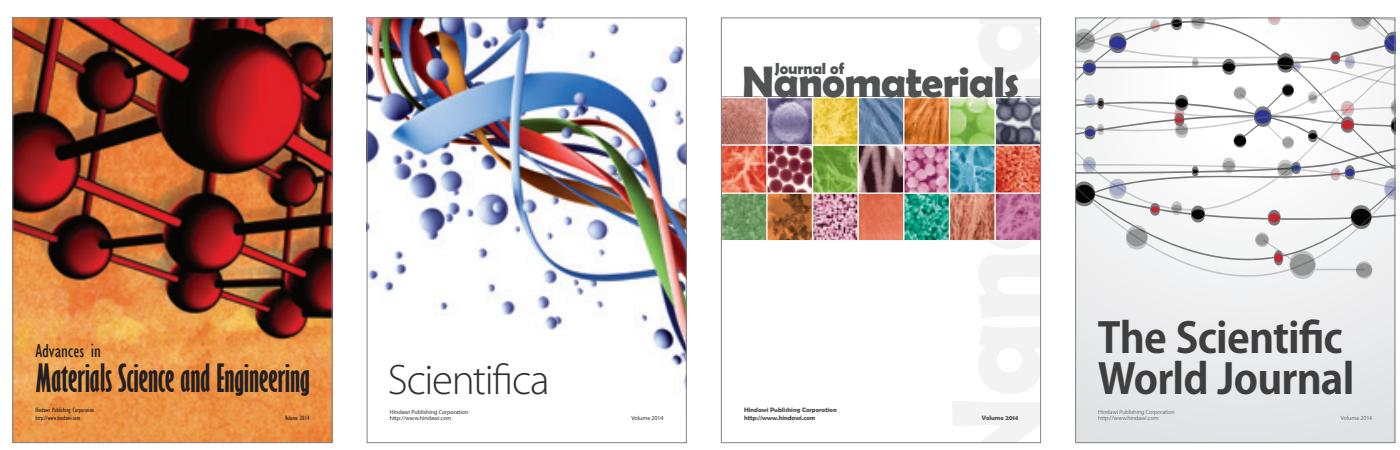

\section{The Scientific World Journal}
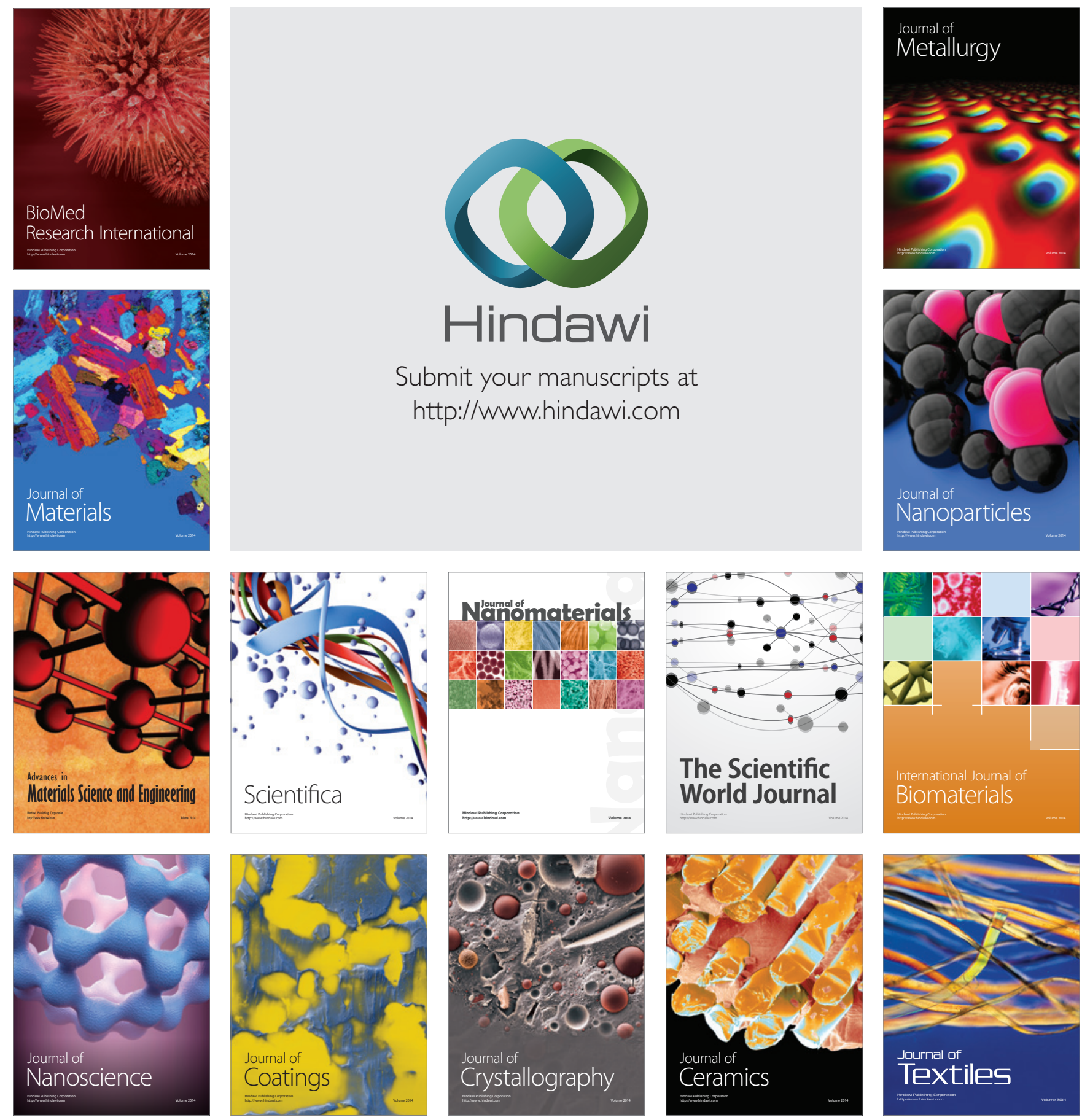